\title{
Assimilation in the risk preferences of spouses
}

Article

Accepted Version

Di Falco, S. and Vieider, F. (2018) Assimilation in the risk preferences of spouses. Economic Inquiry, 56 (3). pp. 18091816. ISSN 1465-7295 doi: https://doi.org/10.1111/ecin.12531 Available at https://centaur.reading.ac.uk/72467/

It is advisable to refer to the publisher's version if you intend to cite from the work. See Guidance on citing.

To link to this article DOI: http://dx.doi.org/10.1111/ecin.12531

Publisher: Wiley

All outputs in CentAUR are protected by Intellectual Property Rights law, including copyright law. Copyright and IPR is retained by the creators or other copyright holders. Terms and conditions for use of this material are defined in the End User Agreement.

\section{www.reading.ac.uk/centaur}

\section{CentAUR}

Central Archive at the University of Reading

Reading's research outputs online 


\title{
Assimilation in the Risk Preferences of Spouses*
}

\author{
Salvatore di Falco ${ }^{1}$ and Ferdinand M. Vieider ${ }^{2}$ \\ ${ }^{1}$ University of Geneva, Switzerland \\ ${ }^{2}$ Department of Economics, University of Reading, UK
}

September 14, 2017

\begin{abstract}
We use correlations in the risk preferences of spouses as a testbed of whether preferences are socially transmitted, rather than being innate as traditionally assumed in economics. We obtain rich measurements of the risk preferences of cohabiting spouses in the rural Ethiopian highlands. This allows us to use correlation coefficients at the level of the couple in regression analysis. We find a strong correlation between the strength of the correlation in risk preferences within a couple and how long a couple has been married. This provides direct evidence for assimilation in the risk preference of spouses, and thus for social transmission of preferences. Assortative mating appears to be less important.
\end{abstract}

Keywords: risk preferences; transmission of preferences; gender effects; household decision making

JEL-classification: C93; D03; D80; O12

${ }^{*}$ We are thankful to Armin Falk for helpful comments. All errors remain ours alone. 


\section{Introduction}

Risk preferences play a fundamental role for almost all economic decisions. It may thus seem all the more surprising that relatively little is known to date on how risk preferences are determined. The lack of evidence on the determination of risk preferences may be explained by a long-held view in economics that preferences are innate, and hence unchangeable. This assumption is now increasingly being challenged in both empirical and theoretical research (Booth and Nolen, 2012; Doepke and Zilibotti, 2014; Klasing, 2014). We add to this debate by presenting direct evidence that the correlation in the risk preferences of spouses is driven by assimilation, rather than by assortative mating.

While assortative mating is compatible with different preference-determination mechanisms - including purely genetic transmission and 'innate' preferences - assimilation can only be explained if preferences can change and react to social cues. Obtaining empirical evidence on the determination of risk preferences is important for a number of reasons. For instance, Galor and Michalopoulos (2012) presented a model in which risk preferences act as a driver of long-term growth processes through their role as determinants of entrepreneurship. While the model takes no explicit position on how risk preferences are determined, the mode of determination has important consequences for the speed with which transitions between different growth regimes may take place (for a discussion, see Bouchouicha and Vieider, 2017). Other models assume directly that preferences can be moulded through education - a view that is incompatible with (fully) innate preferences (Doepke and Zilibotti, 2014; Klasing, 2014)

It has been known for some time that preferences are correlated within the family (Charles and Hurst, 2003; Kimball, Sahm and Shapiro, 2009; Alan, Baydar, Boneva, Crossley and Ertac, 2017). Cesarini, Dawes, Johannesson, Lichtenstein and Wallace (2009) and Zhong, Chew, Set, Zhang, Xue, Sham, Ebstein and Israel (2009) presented evidence of genetic transmission of risk preferences from parents to their children in twinstudies. However, the estimated strength of the effect differs considerably between the two studies, and the studies did not exclude cultural transmission as a mechanism acting on top of and beyond any genetic factors. In a seminal paper, Dohmen, Falk, Huffman and Sunde (2012) used a data set representative of the German population to show that risk preferences are highly correlated within couples, as well as between parents and children (see also Kimball et al., 2009). They concluded that such similarities in the 
couple were likely due to positive assortative mating, i.e. the selection of partners based on similar risk preferences.

This conclusion was reached based on the observation that correlations in the risk preference of spouses did not differ between groups of couples that had been married for different lengths of time. Such a method may, however, suffer from several weaknesses. For one, marriage usually follows several years of dating and cohabitation in the West, and the initial years of a relationship may be particularly important when it comes to the assimilation of preferences. There may also be selection issues at play, since people who are particularly risk tolerant are likely to get married later, if at all, and may stay married with a lower likelihood (Schmidt, 2008). Last but not least, the partition of couples into different subgroups does not allow for any controls to be added, so that potential differences between groups may distort the picture.

We revisit the issue of how correlations in the risk preferences of spouses may be explained using a different approach. We obtain rich, incentivised measures of risk preferences at the individual level (as well as survey measures aimed at replicating previous results). This allows us to calculate a correlation coefficient at the level of the couple, which we can then regress on how long a couple has been together while controlling for a number of potential confounding factors. We do this in a randomly selected sample of couples of the rural Ethiopian highlands. Other than in most Western countries, couples in Ethiopia do generally not cohabit before marriage, and divorce is virtually unheard of, eliminating some potential confounds in Western data.

We start by replicating a number of results observed in the previous literature. We find strong correlations in the couple using aggregate measures, which hold both with our incentivised measures and using hypothetical survey measures employed in the previous literature. We also obtain results indicating that risk preferences are similar for geographically proximate counterfactual couples - yet another factor indicative of cultural transmission. We find no difference in the overall risk preferences of men and women within our couples in our incentivised measures, which is consistent with recent evidence showing that gender effects may be dependant on subtle social clues (Booth and Nolen, 2012). We do, however, find a strong gender effect based on the survey question, indicating that gender effects may be task-dependent (Filippin and Crosetto, 2015). Regressing the couple-level correlation coefficient on the average age of the spouses, taken to be a proxy for how long the couple has been married, we find a strong effect indicating that 
the correlation increases in this indicator. This effect is stable to inserting a number of controls. We conclude the paper by discussing the implications of this finding.

\section{Experimental setup and method}

The data were collected in the context of a larger survey study collecting data from 1000 households in the wider Nile Basin in Ethiopia. The study area included four regions of the Ethiopian highlands, in which twenty Woredas (administrative districts) were selected in a stratified selection process based on representation of agro-climatic zones. From each Woreda, 50 households were randomly selected from municipal household lists. We then randomly selected 350 couples from all couples who took part in the survey. Three couples could not be found at home after repeated visits, which leaves us with a complete sample of 347 couples (694 individuals). All experiments and surveys were run in May and June 2013.

Ethiopia has some characteristics that make it well suited for the investigation of our topic. For one, couples typically start cohabiting only after marriage, which minimises issues of previous cohabitation confounding findings. Divorce is virtually inexistent, which excludes confounds deriving from higher divorce rates amongst poorly matched couples. Marriage age is almost universally young, with a median marriage age of 16 years for women and of 24 years for men (ORC, 2006). This makes the average age in the couple a good proxy for how long a couple has been married. Relatively little rural-torural migration means that we can test for the similarity of preferences by geographical proximity (Dercon and Porter, 2014; Di Falco and Bulte, 2013).

We elicit certainty equivalents $(C E s)$ to measure risk preferences (Abdellaoui, Baillon, Placido and Wakker, 2011; Bruhin, Fehr-Duda and Epper, 2010; Sutter, Kocher, GlätzleRützler and Trautmann, 2013). CEs are easy to explain, and the sure amounts of money to be used are naturally limited between the lower and upper amount of the prospect. They are also amongst the simplest risk elicitation tasks one can conceive of - a great advantage in developing countries, where a large part of the population is illiterate or unaccustomed to abstract tasks (Vieider, Beyene, Bluffstone, Dissanayake, Gebreegziabher, Martinsson and Mekonnen, 2016; Vieider, 2017).

Overall, we elicited 14 CEs per subject using binary prospects varying in probabilities and outcomes. The design follows the one employed by Vieider, Lefebvre, Bouchouicha, 
Chmura, Hakimov, Krawczyk and Martinsson (2015) with students across 30 countries, but we restricted ourselves only to known probabilities and gains due to time constraints (the exact characteristics of the prospects can be gathered from table A in the appendix). Every time a major change occurred in the decision tasks (e.g. a change in probabilities or outcomes, or from gains to losses), the enumerator pointed out the change and gave additional explanations of what this would involve. In the course of the explanation, subjects were also shown bags containing numbered ping pong balls that would be used for the random extraction, and were encouraged to examine their contents. This served to make the decision problems more tangible and concrete.

The prospects were presented to subjects in a fixed order, whereby first 50-50 prospects were presented in order of ascending expected value, and then the remaining prospects were presented in order of increasing probability. The fixed order was kept so as to make the task less cognitively demanding for subjects, since in the fixed ordering only one element would change from one decision task to the next, which could be easily pointed out by the enumerator. To test whether such a fixed ordering of tasks might influence decisions, we ran a large-scale pilot involving 330 subjects. ${ }^{1}$ The pilot revealed no differences between the fixed ordering used here and a random ordering.

CEs were elicited in individual interviews by a team of 20 enumerators. The enumerators were extensively trained before going to the field, and acquired experience by running pilot experiments. The experiment was preceded by a careful explanation of the decision tasks. Subjects were told that they would face choices between amounts of money that could be obtained for sure and risky allocations. At the end, one of the tasks would be extracted at random, and one of the choices between a sure amount and the prospect would be played for real money (the standard procedure in this type of task). A risk neutral decision maker stood to win the PPP-equivalent of $€ 18$ - a substantial sum in Ethiopia, corresponding to an income of about two weeks for the median participant. The experiments in the couple were generally run at the same time. First, the two spouses were separated so that they could not see or hear each other's decisions. Two enumerators would then elicit the risk preferences of the spouses at the same time. The payouts took place separately, and discretely out of sight from the spouse.

\footnotetext{
${ }^{1}$ The pilot was run in Vietnam at at Ho-Chi-Minh-City University as it was meant to inform a number of experiments to be conducted with the same type of tasks. This also explains the large number of subjects in the pilot, which were included to guarantee enough statistical power to make this test meaningful.
} 
We also asked subjects about their willingness to take risks to obtain an alternative measure of risk taking behaviour. The question has been validated by Dohmen, Falk, Huffman, Sunde, Schupp and Wagner (2011) for a representative sample of the German population, and by Vieider et al. (2015) for an international sample of students across 30 countries (see also Hardeweg, Menkhoff and Waibel, 2013, for a validation in a rural population sample of Thailand). The question reads as follows:

How do you see yourself? Are you generally a person who is fully willing to take risks or do you try to avoid taking risks? Please tick a box on the scale below, where 0 means "risk averse" and 10 means "fully prepared to take risks":

\begin{tabular}{ccccccccccc} 
risk averse & & & & & & & & \multicolumn{2}{c}{$\begin{array}{c}\text { fully prepared } \\
\text { to take risks }\end{array}$} \\
\hline 0 & 1 & 2 & 3 & 4 & 5 & 6 & 7 & 8 & 9 & 10 \\
\hline $\mathrm{O}$ & $\mathrm{O}$ & $\mathrm{O}$ & $\mathrm{O}$ & $\mathrm{O}$ & $\mathrm{O}$ & $\mathrm{O}$ & $\mathrm{O}$ & $\mathrm{O}$ & $\mathrm{O}$ & $\mathrm{O}$ \\
\hline
\end{tabular}

We normalise our CEs to make them more comparable across prospects. We use $\tau_{i}=\frac{c e_{i}-y_{i}}{x_{i}-y_{i}}$ as a measure of risk tolerance, where $x_{i}$ is the high outcome in prospect $i$ and $y_{i}$ is the low outcome, so that $x_{i}>c e_{i}>y_{i}$. This makes sure that our measure is always contained within the unit interval, which reduces distortions in the correlation analysis due to different ranges in the prospects. The normalised risk tolerance can be compared directly to the probability of winning $p_{i}$, with $\tau_{i}>p_{i}$ indicating risk seeking, $\tau_{i}=p_{i}$ risk neutrality, and $\tau_{i}<p_{i}$ risk aversion. ${ }^{2}$

\section{Results}

\subsection{Descriptive data and gender effects}

Descriptives of risk preferences are shown in figure 1, separately for the male household heads and their spouses. To avoid informational overload, the graph shows only risk tolerance for prospects resulting in either $€ 20$ or $0 \mathrm{PPP}$, by probability level (results for other prospects are similar and can be found in the appendix). Both spouses display a tendency towards risk seeking for most probabilities, as can be seen by directly comparing

\footnotetext{
${ }^{2}$ To see this, one can interpret our risk tolerance indicator $\tau$ as a decision weight capturing nonlinear transformations of probabilities under dual-expected utility (Yaari, 1987). Since utility is linear in that setup, we can represent preferences over a given prospect $i$ as $c e_{i}=\tau_{i} x_{i}+\left(1-\tau_{i}\right) y_{i}$. Solving this equation for $\tau_{i}$ then yields our risk tolerance index. Notice that since $\tau_{i}$ is a decision weight attached to the best outcome in the prospect, $\tau_{i}>p_{i}$ will now immediately indicate risk seeking. Notice also, however, that we use this purely as a model-free index, and that different normalizations do not substantively affect our results.
} 
the normalised risk tolerance to the probability of winning. Only for the prospect offering the largest probability of winning do we observe slight risk aversion. This corresponds to previous evidence from the Ethiopian highlands obtained by Vieider et al. (2016). It amounts to a generalisation to the overall trends found in international comparisons using student data (L'Haridon and Vieider, 2016), which found students from poorer countries to be systematically more risk tolerant than students from rich countries.

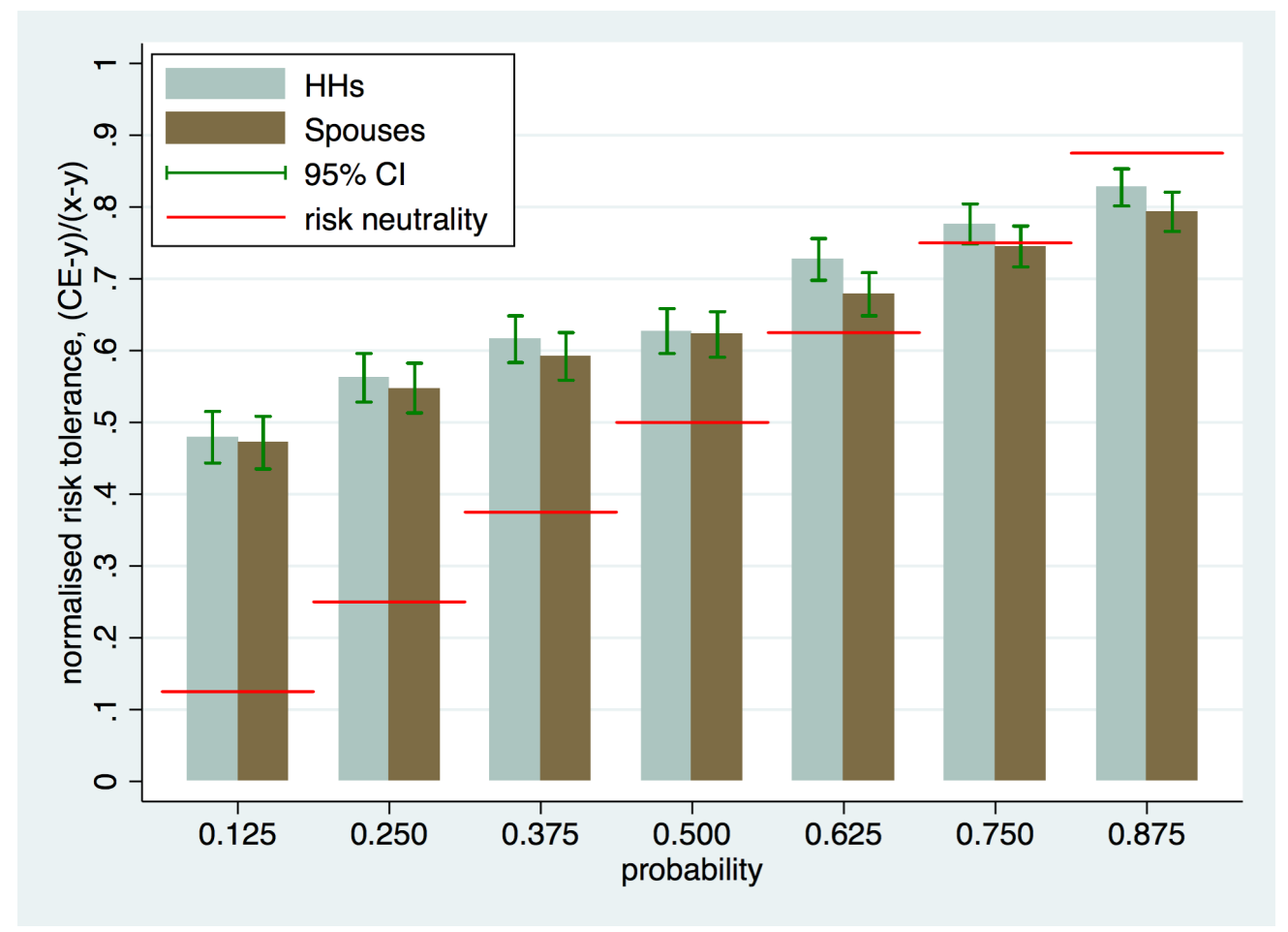

Figure 1: Risk premia by prospect and gender, for $\left(20, p_{i} ; 0\right)$

We detect no difference in risk tolerance between spouses taking the average of the 14 indices of risk tolerance $(z=1.584, p=0.113$; signed-rank test). In individual prospects there are no differences between spouses up to and including a probability of 0.5. For larger probabilities, however, women are somewhat more risk averse than their husbands (statistics and tests for all the prospects can be found in appendix A). This corresponds to findings in structural models showing that gender effects may interact with the probability of winning in a prospect, rather than having a uniform effect on risk preferences (L'Haridon and Vieider, 2016). It is also consistent with recent evidence from a large meta-analysis showing that gender effects may be weak or non-existent when measured in multiple choice lists (Filippin and Crosetto, 2015). The results show that gender effects may vanish once one keeps the economic background characteristics 
constant. Comparing male and female household heads in Ethiopia, Vieider et al. (2016) found large differences, which are likely driven by the economic vulnerability of female household heads.

Our findings stand in marked contrast to those of Dohmen et al. (2012), who found strong gender effects within the couple, with women more risk averse than men. To determine whether the difference in findings is due to the differences in tasks or differences in subject pools, we further examine the gender effect in terms of self-declared willingness to take risks. We find a significant correlation between our average incentivised measure and self-declared willingness to take risk for both men $(\rho=0.235, p<0.001$; Spearman rank correlation) and women $(\rho=0.182, p<0.001)$. Other than for our incentivised measures, self-declared willingness to take risks is significantly lower for women than for men $(z=3.425, p<0.001$, signed-rank test $)$. The difference with the findings of Dohmen et al. (2012) thus appears to derive from the task used rather than from the subject sample.

\subsection{Correlation analysis using aggregate measures}

We start by examining aggregate risk preferences, using the simple mean of the 14 risk tolerance measures per subject. The correlations we find within the couple are relatively strong, with Pearson's $r=0.498, p<0.001$ (we use Pearson correlations inasmuch as we are interested in absolute similarities beyond ranks; all results are stable if we use Spearman correlations instead). Kimball et al. (2009) reported a correlation in the couple of 0.41 based on a hypothetical task gauging risk taking in labor markets. Dohmen et al. (2012) found a correlation of 0.34 in a representative sample of the German population using the survey question on general willingness to take risks. Our measure, being a mean of several CEs, is likely less affected by noise than either of those measures. It also has a finer resolution. Using the qualitative scale instead, we find a correlation of $r=0.335, p<0.001$, which is almost identical to the one in the German sample.

We next explore the measure for the 120,062 counterfactual couples obtained by pairing all household heads with all spouses but their own. This allows us to establish a baseline, and to rule out that correlations in our aggregate measure are purely driven by mechanical factors. We would expect the correlations for these artificial pairings to be zero on average, which is indeed what we find: $r=-0.001, p=0.566$ (the same holds 
for the willingness to take risk question: $r=-0.001, p=0.748)$. This serves to reassure us that the correlation we found above was indeed genuine.

Having established this benchmark, we can now further explore the correlations by subgroups of the counter-factual couples. We start from the regional level. We have four regions in our sample, Tigray (64 couples), Amhara (80 couples), Oromiya (157 couples), and SNNP (43 couples). Including only counterfactual pairings with both spouses from the same region $(N=33,118)$, we obtain a correlation coefficient of $r=0.116, p<0.001$. If we further reduce our geographical focus to the level of the Kebele (an administrative district; $N=12,374)$, the correlation further increases to $r=0.234, p<0.001$. The smallest administrative level in our data is the Got, or village level. If we only consider counterfactual couples at this level $(N=2,480)$, the correlation further increases to $r=0.261, p<0.001$. This provides a first, albeit very indirect, indication that risk preferences may be subject to socially driven assimilation.

\subsection{Determinants of within-couple correlations}

The next step will be to investigate the determinants of the correlations in real couples. To this end, we calculate correlation coefficients at the level of the couple. Table 1 shows a regression of our 347 correlation coefficients on background characteristics of the couple. We are most interested in age, which is taken to be the average age of the couple, and normalised to be 0 for the youngest couple in our sample. At 20.5 years, the average age of the youngest couple is indeed almost identical to the statistical age of the median Ethiopian couple (ORC, 2006). We take this variable to serve as a proxy for how long a couple has been married, since we do not have direct data on this. In case of assortative mating, we would expect there to be no effect of age on the correlation. If, on the other hand, the correlation is due to assimilation, then we would expect a positive correlation with average age.

Regression I shows that age has a strong positive effect on the correlation of risk preferences between spouses. Regression II adds age squared to look for non-linear effects, but finds none. Regression III further adds the age difference in the couple, which also shows no effects. Finally, regression IV adds land size (which serves as an income proxy - see Vieider et al., 2016, for a detailed discussion of this issue for Ethiopia), and a variable capturing the difference in literacy within the couple. These controls serve the 
purpose of determining whether it is purely income effects that drive similarities in the risk preferences of couples over time. None of these variables shows an effect, indicating that the correlations are not purely driven by income effects. The age effect remains strong and highly significant throughout. The effect is also stable to using the age of either spouse instead of the average age in the couple.

Table 1: Regressions of correlation coefficients, real couples

\begin{tabular}{|c|c|c|c|c|}
\hline & I & II & III & IV \\
\hline mean age norm & $\begin{array}{c}0.007^{* * *} \\
(0.002)\end{array}$ & $\begin{array}{c}0.007^{* * *} \\
(0.002)\end{array}$ & $\begin{array}{c}0.007^{* * *} \\
(0.002)\end{array}$ & $\begin{array}{c}0.008^{* * *} \\
(0.002)\end{array}$ \\
\hline mean age sqr & & $\begin{array}{l}-0.002 \\
(0.012)\end{array}$ & $\begin{array}{l}-0.001 \\
(0.012)\end{array}$ & $\begin{array}{l}-0.007 \\
(0.012)\end{array}$ \\
\hline age diff & & & $\begin{array}{c}0.000 \\
(0.003)\end{array}$ & $\begin{array}{l}-0.000 \\
(0.003)\end{array}$ \\
\hline land size & & & & $\begin{array}{l}-0.037 \\
(0.025)\end{array}$ \\
\hline literacy diff & & & & $\begin{array}{l}-0.006 \\
(0.029)\end{array}$ \\
\hline constant & $\begin{array}{c}0.313^{* * *} \\
(0.050)\end{array}$ & $\begin{array}{c}0.312^{* * *} \\
(0.050)\end{array}$ & $\begin{array}{c}0.311^{* * *} \\
(0.058)\end{array}$ & $\begin{array}{c}0.297^{* * *} \\
(0.067)\end{array}$ \\
\hline$N$ & 345 & 345 & 345 & 323 \\
\hline$R^{2}$ & 0.034 & 0.034 & 0.030 & 0.041 \\
\hline
\end{tabular}

The average age variable used is normalised such that the youngest couple in our data set corresponds to 0 . The constant in regression I may thus be interpreted as the correlation found for the youngest couple in our data, which presumably got married very recently. At 0.313 , that value is not much larger than the correlation found for counterfactual couples from the same administrative district or Kebele, which is $r=0.310 .^{3}$ Indeed, the two are not significantly different at conventional levels $(z=1.641, p=$ $0.101, N=12,180)$. This seems to indicate that assortative mating does not play a strong role in our sample to start with.

One may be concerned about differential age effects on risk preferences for men and women. Such differential age effects may conceivably push the preferences of spouses to resemble each other increasingly over time, without this effect being due to true assimilation. To rule out such effects, table 2 shows separate regressions of risk attitudes on age and other characteristics for the household head and spouse separately. Neither age nor being literate show any effects in regression I. Regression II adds land size as a proxy for income. Risk tolerance is strongly increasing in land owned, in accordance

\footnotetext{
${ }^{3}$ The couple-level correlations are higher than the aggregate correlations discussed above. This derives from the fact that the lotteries employed have certain chracteristics that produce a positive base correlation due to both mechanical and behavioural factors.
} 
with most previous evidence. ${ }^{4}$ Finally, we add steepness of the land and total wealth as additional controls. Steepness usually lowers the productivity of land in the Ethiopian highlands, and we find the expected negative effect on risk tolerance. Wealth shows no significant effect. Notwithstanding these significant correlates, the variance explained in the regression remains very low-large amounts of unexplained heterogeneity are indeed the norm for risk preferences (von Gaudecker, van Soest and Wengström, 2011). Most importantly, however, the predictors are perfectly aligned for the spouses, making purely mechanical causes for correlations unlikely.

Table 2: Regressions of risk tolerance, HHs and spouses

\begin{tabular}{|c|c|c|c|c|c|c|}
\hline & \multicolumn{2}{|c|}{ I } & \multicolumn{2}{|c|}{ II } & \multicolumn{2}{|c|}{ III } \\
\hline & $\mathrm{HH}$ & SP & $\mathrm{HH}$ & SP & $\mathrm{HH}$ & SP \\
\hline age & -0.004 & -0.019 & -0.009 & -0.024 & -0.009 & -0.025 \\
\hline & $(0.014)$ & $(0.015)$ & $(0.013)$ & $(0.015)$ & $(0.013)$ & $(0.015)$ \\
\hline literate & 0.030 & 0.031 & 0.023 & 0.026 & 0.014 & 0.021 \\
\hline & $(0.029)$ & $(0.035)$ & (0.028) & $(0.037)$ & (0.028) & $(0.037)$ \\
\hline land size & & & $\begin{array}{c}0.060^{* * *} \\
(0.011)\end{array}$ & $\begin{array}{c}0.052^{* * *} \\
(0.015)\end{array}$ & $\begin{array}{c}0.055^{* * *} \\
(0.012)\end{array}$ & $\begin{array}{c}0.052^{* * *} \\
(0.015)\end{array}$ \\
\hline steep & & & & & $\begin{array}{c}-0.493^{* * *} \\
(0.093)\end{array}$ & $\begin{array}{c}-0.376^{* * *} \\
(0.091)\end{array}$ \\
\hline total wealth & & & & & $\begin{array}{c}0.016 \\
(0.012)\end{array}$ & $\begin{array}{c}0.001 \\
(0.018)\end{array}$ \\
\hline constant & $\begin{array}{c}0.640^{* * *} \\
(0.021)\end{array}$ & $\begin{array}{c}0.631^{* * *} \\
(0.017)\end{array}$ & $\begin{array}{c}0.642^{* * *} \\
(0.021)\end{array}$ & $\begin{array}{c}0.630^{* * *} \\
(0.016)\end{array}$ & $\begin{array}{c}0.651^{* * *} \\
(0.020)\end{array}$ & $\begin{array}{c}0.635^{* * * *} \\
(0.017)\end{array}$ \\
\hline$N$ & 342 & 327 & 336 & 321 & 336 & 321 \\
\hline$R^{2}$ & 0.005 & 0.010 & 0.061 & 0.048 & 0.099 & 0.068 \\
\hline
\end{tabular}

\section{Conclusion}

Risk preferences have been found to be highly correlated within the couple, as well as between parents and children. What drives such correlations promises to shed light on the determinants of risk preferences more in general. Genetic explanations might suggest that preferences are innate (Cesarini et al., 2009). Such an account would also be consistent with positive assortative mating within the couple. By showing direct evidence for the assimilation of risk preferences within the couple, we posit that risk preferences can change over time and adapt to changing circumstances. This is consistent with accounts showing the dependence of risk preferences on subtle social clues (Booth and

\footnotetext{
${ }^{4}$ There exists a sprawling literature on the correlation between income or wealrth and risk aversion. Although economists generally expect an effect in the direction of risk aversion declining in income, this relationship is less well-established empirically than one might think. See Hopland, Matsen and Strøm (2013) and ? for a discussion.
} 
Nolen, 2012; Booth, Cardona-Sosa and Nolen, 2014). The results thus support theories that rely on quick transitions in risk preferences between generations, with preferences either consciously instilled by parents into children to adapt to economic circumstances (Doepke and Zilibotti, 2014; Klasing, 2014), or transmitted culturally with potential tipping points accelerating the spread.

Our conclusion of assimilation being the main driver of the correlation of risk preferences in the couple departs from the conclusions reached in previous studies. In particular, Dohmen et al. (2012) concluded that the correlation of risk preferences found within couples is due to assortative mating. They based this conclusion on splitting their sample into sub-samples that had been married for relatively short and for much longer periods, and then compared the correlation coefficients. They concluded that the coefficients were very similar, taking this as evidence for assortative mating. Reanalysing the same data and using the same technique of splitting the sample into different age groups, but using different econometric techniques accounting for errors, Bacon, Conte and Moffatt (2014) found some evidence for correlations increasing in years of marriage. They nevertheless concluded that positive assortative mating was the main factor underlying correlations in the risk preferences of couples.

The difference in our results may stem from a number of factors. For one, even recently married couples may have been together and may have cohabited for long periods in Germany. The same is very unlikely to be true in Ethiopia. Furthermore, simply comparing correlations in two different groups is a relatively coarse method for determining potential effects of assimilations, as the groups may differ along other dimensions that cannot be controlled for. We can directly estimate the effect of years of marriage (as proxied by average age in the couple) on the couple-level correlation coefficient. This is clearly a much more powerful method, given how it allows for a much finer determination of the effect of marriage time on correlation coefficients, wile simultaneously inserting controls into the regression. Nevertheless, further corroboration of these results using different methods seems highly desirable. 


\section{A Comparison of risk premia in the couple by prospect}

Table 3: Summary measures of aggregate risk preferences by prospect

\begin{tabular}{crrrcc}
\hline$p$ & $x$ & $y$ & $\frac{c e_{i}-y_{i}}{x_{i}-y_{i}}$ HHs & $\frac{c e_{i}-y_{i}}{x_{i}-y_{i}}$ spouses & Ranksum test \\
\hline 0.50 & 40 & 0 & 0.712 & 0.726 & $z=-0.298, p=0.765$ \\
0.50 & 80 & 0 & 0.671 & 0.665 & $z=1.129, p=0.259$ \\
0.50 & 160 & 0 & 0.627 & 0.622 & $z=0.781, p=0.435$ \\
0.50 & 240 & 0 & 0.595 & 0.591 & $z=1.217, p=0.223$ \\
0.50 & 240 & 80 & 0.591 & 0.575 & $z=0.936, p=0.334$ \\
0.50 & 240 & 160 & 0.621 & 0.632 & $z=-0.735, p=0.462$ \\
0.125 & 160 & 0 & 0.306 & 0.296 & $z=0.956, p=0.339$ \\
0.125 & 160 & 40 & 0.653 & 0.650 & $z=0.470, p=0.638$ \\
0.250 & 160 & 0 & 0.562 & 0.548 & $z=1.028, p=0.304$ \\
0.375 & 160 & 0 & 0.616 & 0.592 & $z=1.680, p=0.093$ \\
0.625 & 160 & 0 & 0.727 & 0.678 & $z=2.833, p=0.005$ \\
0.750 & 160 & 0 & 0.776 & 0.745 & $z=1.912, p=0.056$ \\
0.875 & 160 & 0 & 0.827 & 0.793 & $z=2.084, p=0.037$ \\
0.875 & 160 & 40 & 0.822 & 0.791 & $z=1.964, p=0.049$ \\
\hline mean & & 0.652 & 0.635 & $z=1.584, p=0.113$ \\
\hline
\end{tabular}




\section{References}

Abdellaoui, Mohammed, Aurélien Baillon, Lætitia Placido, and Peter P. Wakker (2011) 'The Rich Domain of Uncertainty: Source Functions and Their Experimental Implementation.' American Economic Review 101, 695-723

Alan, Sule, Nazli Baydar, Teodora Boneva, Thomas F. Crossley, and Seda Ertac (2017) 'Transmission of risk preferences from mothers to daughters.' Journal of Economic Behavior \& Organization 134, 60-77

Bacon, Philomena M., Anna Conte, and Peter G. Moffatt (2014) 'Assortative mating on risk attitude.' Theory and Decision 77(3), 389-401

Booth, Alison L., and Patrick Nolen (2012) 'Gender differences in risk behaviour: does nurture matter?' The Economic Journal 122(558), F56-F78

Booth, Alison, Lina Cardona-Sosa, and Patrick Nolen (2014) 'Gender differences in risk aversion: Do single-sex environments affect their development?' Journal of Economic Behavior \& Organization 99, 126-154

Bouchouicha, Ranoua, and Ferdinand M. Vieider (2017) 'Growth, Entrepreneurship, and Risk Tolerance: A risk-income paradox.' University of Reading Working Paper

Bruhin, Adrian, Helga Fehr-Duda, and Thomas Epper (2010) 'Risk and Rationality: Uncovering Heterogeneity in Probability Distortion.' Econometrica 78(4), 1375-1412

Cesarini, David, Christopher T. Dawes, Magnus Johannesson, Paul Lichtenstein, and Björn Wallace (2009) 'Genetic Variation in Preferences for Giving and Risk Taking.' Quarterly Journal of Economics 124(2), 809-842

Charles, Kerwin Kofi, and Erik Hurst (2003) 'The Correlation of Wealth Across Generations.' Journal of Political Economy 111(6), 1155-1182

Dercon, Stefan, and Catherine Porter (2014) 'Live Aid Revisited: Long-Term Impacts of the 1984 Ethiopian Famine on Children.' Journal of the European Economic Association 12(4), 927-948

Di Falco, Salvatore, and Erwin Bulte (2013) 'The Impact of Kinship Networks on the Adoption of Risk-Mitigating Strategies in Ethiopia.' World Development 43, 100-110

Doepke, Matthias, and Fabrizio Zilibotti (2014) 'Culture, Entrepreneurship, and Growth.' In 'Handbook of Economic Growth,' vol. 2

Dohmen, Thomas, Armin Falk, David Huffman, and Uwe Sunde (2012) 'The Intergenerational Transmission of Risk and Trust Attitudes.' Review of Economic Studies 
$70(2), 645-677$

Dohmen, Thomas, Armin Falk, David Huffman, Uwe Sunde, Jürgen Schupp, and Gert G. Wagner (2011) 'Individual Risk Attitudes: Measurement, Determinants, and Behavioral Consequences.' Journal of the European Economic Association 9(3), 522-550

Filippin, Antonio, and Paolo Crosetto (2015) 'A Reconsideration of Gender Differences in Risk Attitudes.' Management Science, forthcoming

Galor, Oded, and Stelios Michalopoulos (2012) 'Evolution and the Growth Process: Natural Selection of Entrepreneurial Traits.' Journal of Economic Theory 147(2), 759 780

Hardeweg, Bernd, Lukas Menkhoff, and Hermann Waibel (2013) 'Experimentally Validated Survey Evidence on Individual Risk Attitudes in Rural Thailand.' Economic Development and Cultural Change 61(4), 859-888

Hopland, Arnt O., Egil Matsen, and Bjarne Strøm (2013) 'Income and choice under risk.' Working Paper Series 14313, Department of Economics, Norwegian University of Science and Technology

Kimball, Miles S., Claudia R. Sahm, and Matthew D. Shapiro (2009) 'Risk Preferences in the PSID: Individual Imputations and Family Covariation.' American Economic Review, Papers and Proceedings 99(2), 363-368

Klasing, Mariko J. (2014) 'Cultural change, risk-taking behavior and implications for economic development.' Journal of Development Economics 110, 158-169

L'Haridon, Olivier, and Ferdinand M. Vieider (2016) 'All over the map: Heterogeneity of risk preferences across individuals, contexts, and countries.' EM-DP2016-04, University of Reading

ORC, Macro (2006) Ethiopia Demographic and Health Survey (Addis Ababa, Ethiopia: Central Statistical Agency)

Schmidt, Lucie (2008) 'Risk preferences and the timing of marriage and childbearing.' Demography 45(2), 439-460

Sutter, Matthias, Martin G Kocher, Daniela Glätzle-Rützler, and Stefan T Trautmann (2013) 'Impatience and Uncertainty: Experimental Decisions Predict Adolescents' Field Behavior.' American Economic Review 103(1), 510-531

Vieider, Ferdinand M. (2017) 'Certainty Preference, Random Choice, and Loss Aversion: A Comment on "Violence and Risk Preference: Experimental Evidence from 
Afghanistan".' American Economic Review, forthcoming

Vieider, Ferdinand M., Abebe Beyene, Randall A. Bluffstone, Sahan Dissanayake, Zenebe Gebreegziabher, Peter Martinsson, and Alemu Mekonnen (2016) 'Measuring risk preferences in rural Ethiopia.' Economic Development and Cultural Change, forthcoming Vieider, Ferdinand M., Mathieu Lefebvre, Ranoua Bouchouicha, Thorsten Chmura, Rustamdjan Hakimov, Michal Krawczyk, and Peter Martinsson (2015) 'Common components of risk and uncertainty attitudes across contexts and domains: Evidence from 30 countries.' Journal of the European Economic Association 13(3), 421-452

von Gaudecker, Hans-Martin, Arthur van Soest, and Erik Wengström (2011) 'Heterogeneity in Risky Choice Behaviour in a Broad Population.' American Economic Review 101(2), 664-694

Yaari, Menahem E. (1987) 'The Dual Theory of Choice under Risk.' Econometrica $55(1), 95-115$

Zhong, Songfa, Soo Hong Chew, Eric Set, Junsen Zhang, Hong Xue, Pak C. Sham, Richard P. Ebstein, and Salomon Israel (2009) 'The Heritability of Attitude Toward Economic Risk.' Twin Research and Human Genetics 12(1), 103-107 